\title{
CONTRIBUIÇÕES PARA O RECONHECIMENTO DE CIDADANIAS CONTEMPORÂNEAS DO E NO CAMPO: UMA ABORDAGEM A PARTIR DA HISTÓRIA DA INFÂNCIA
}

\author{
Franciele Clara Peloso ${ }^{1}$
}

Resumo: Este estudo tem como objetivo fazer uma discussão sobre o reconhecimento de cidadanias contemporâneas a partir das Infâncias do e no Campo. A justificativa desta pesquisa está voltada à necessidade de dar visibilidade às diferentes infâncias e legitimar as experiências vivenciadas pelas pessoas situadas em contextos históricos marcados pela desigualdade social, igualmente evidenciar a diversidade de espaços, de culturas de classe, étnicas, raciais, dentre outras em que a infância acontece. Trata-se de um ensaio teórico. As principais considerações deste estudo sublinham as heterogeneidades relevadas pelas distintas infâncias e formas de ser crianças. Da mesma forma evidenciam a invisibilização e o ocultamento de experiências infantis que foram segregadas ao longo da história e continuam sendo quando homogeneizadas por uma concepção de infância de origem europeia, branca, cristã e urbana. A principal contribuição deste estudo consiste no reconhecimento da existência das infâncias invisibilizadas ou pouco consideradas, igualmente do reconhecimento das cidadanias contemporâneas, acompanhado do desejo de inspirar pesquisadores/as a considerar e potencializar as Infâncias do e no Campo em seus estudos e em ações deles decorrentes.

Palavras-chave: Infâncias. Campo. Educação do e no Campo. Cidadanias Contemporâneas. Diversidade.

Doutora em Educação pela UFSCar. Professora Adjunta da Universidade Tecnológica Federal do Paraná. Líder do Núcleo de Estudos Freirianos de Investigação e Ação Social (NEFIAS) vinculado ao Grupo de Estudos Educação, Diversidade e Inclusão (UTFPR/PB). Integrante do Grupo de Estudos e Pesquisa em Educação: teoria e prática (GEPE) da UNESPAR/UV. Integrante do Grupo de Estudos Práxis Educativa: saberes e fazeres na/da Educação Infantil (UNICENTRO). Email: clara@utfpr.edu.br. 


\section{INTRODUÇÃO}

Os diversos intelectuais que estudam questões relacionadas à História da Infância (SARMENTO, 2008; MULLER, 2007; VASCONCELOS; SARMENTO, 2007; KRAMER, 2003, entre outros), Freitas e Kuhlmann Junior (2002), e Sarmento (2007) enfatizam que, na História da Infância, o campo das definições epistemológicas é bastante extenso e já consolidado. No entanto, essa mesma história apresenta abordagens genéricas e imprecisas quando se reporta a discussões que contextualizam a infância em diferentes contextos sociais, logo também é genérica a discussão sobre políticas destinadas à infância que garantam a sua cidadania.

Um dos grandes avanços do campo de estudos que coloca a infância e seus entornos como tema de análise, além de expor e definir as concepções de infância, é valorizar as experiências infantis, bem como empreender denúncias e anúncios sobre as crianças e suas infâncias.

Os estudiosos da historiografia da infância (FREITAS, 2011; FREITAS, KUHLMANN JUNIOR, 2002, e outros) afirmam a necessidade de discutir questões relacionadas ao processo educativo relativo a infância considerando diferentes fatores, que abarcam tanto os fatores biológicos, que apontam para características fisiológicas e anatômicas específicas, como também fatores de ordem social, cultural, de gênero, de raça, dentre outros, pois a partir deles podemos identificar diferentes concepções de infância. Uma vez que, de acordo com Müller (2007) as concepções sobre a infância resultam de todo um contexto social, pautado por regras e valores que são construídos historicamente e podem estar relacionados aos valores sociais dominantes em cada sociedade.

O objetivo deste artigo é problematizar sobre as diferentes concepções de infância, com foco nas Infâncias do e no Campo no sentido de provocar uma discussão que oportunize um repensar sobre a concepção de normalidade a respeito da infância e das crianças e que também permita o reconhecimento das cidadanias contemporâneas do e no campo, uma vez que concepção socialmente considerada ideal nunca representou a totalidade de realidades infantis. É importante destacar que as ideias contidas nesse estudo são parte integrante de uma tese de doutorado (PELOSO, 2015) ${ }^{2}$, na qual discutimos,

Tratou-se de pesquisa de doutorado, intitulada Infâncias do e no Campo: um retrato dos estudos pedagógicos nacionais, defendida junto ao Programa de Pós-Graduação em Educação, da Universidade Federal de São Carlos, em fevereiro de 2015. Tal pesquisa de doutorado esteve inserida em pesquisa maior, coordenada pela orientadora Profa. Dra. Roseli Rodrigues de Mello, dedicada a 
sobretudo, quais concepções sobre as Infâncias do e no Campo estão sendo difundidas academicamente e quais aportes teóricos e metodológicas dão suporte para a socialização dessas concepções.

\section{CONCEPÇÕES DE INFÂNCIA: ARGUMENTOS PARA PAUUTAR AS INFÂNCIAS DO CAMPO}

A partir de um olhar histórico (RAMOS, 2007; PRIORE, 2007; FREITAS, KUHLMANN JUNIOR, 2002) é possível perceber uma pluralidade de jeitos de ser criança em diferentes infâncias. No entanto, podemos afirmar com base nos estudos de Ariès (1981) que, por muito tempo, academicamente se buscou uma unanimidade relativa à concepção de infância. Essa ideia esteve vinculada e foi alimentada em diferentes veículos do cotidiano: nos estudos acadêmicos, na política, na religião, na cultura, na educação, dentre outros campos. Essa concepção unânime de infância ignorou dimensões básicas de existência como sexo, classe social, cultura, espaço físico e geográfico onde a criança vivia/estava. Sarmento (2008) assevera que essa concepção dominante construída sobre a infância invisibiliza experiências infantis e suas formas de ser e estar no mundo.

Arroyo e Silva (2012) afirmam que os atuais estudos sobre a infância ampliam as discussões e discutem o status das crianças em âmbito social como sujeitos produtores de cultura, de experimentação, de intencionalidade, de produção de saberes, valores e conhecimentos. Essa forma de conceber a infância está diretamente relacionada à corrente denominada Sociologia da Infância e implica o reconhecimento de que há uma pluralidade de infâncias e jeitos de ser criança. Da mesma forma nos possibilita refutar a ideia de concepção única ou ideal sobre a infância socializada historicamente.

Essa afirmação vem ao encontro dos estudos realizados e fundamentos a partir dos pressupostos da Sociologia da Infância. É a partir desses estudos que as crianças são concebidas e afirmadas como sujeitos/atores sociais e a infância como espaço de produção de cultura. Conforme assegura Sarmento (2008), são dois os objetos de estudo da Sociologia da Infância: 1) as crianças como atores sociais em seus modos de ser e estar no mundo; e 2) a infância como categoria social do tipo geracional, socialmente construída.

Os estudos de Abramowicz e Oliveira (2010), identificam que é a partir dos

analisar as contribuições da produção acadêmica brasileira para os avanços na educação escolar (MELLO, 2012). 
anos de 1980 que os trabalhos sobre a infância, com caráter sociológico se multiplicaram. As autoras explicam que a Sociologia, até então, não tinha reservado às crianças uma atenção específica. Um dos principais conceitos da Sociologia - a socialização - esteve atrelado, majoritariamente, aos pressupostos de Durkheim, calcados em uma perspectiva estrutural-funcional e isso subjugava as crianças ao modelo e ao processo de socialização das pessoas adultas. As crianças eram estudadas como um fenômeno interligado à escola e à família e diretamente associadas às reflexões sobre sua socialização como uma forma de imposição dos valores da sociedade adulta.

Sob essa perspectiva, a partir de uma concepção freiriana, compreendemos a infância como condição para a experiência humana. Essa compreensão propicia o entendimento da criança como alguém que é e está sendo no mundo, com o mundo e as outras pessoas.

No período da infância é possível observar práticas opressoras que descaracterizam a infância como condição para experiência humana, bem como desconfiguram suas cidadanias. As formas de opressão podem se manifestar a partir de diferentes dimensões, seja com base na classe social, no sexo, no gênero, na etnia, na cultura, nas instituições sociais a que pertencem e se relacionam, a partir dos meios de comunicação e da mídia, bem como nos espaços geográficos/territoriais em que habitam, dentre outros.

Nos últimos anos, as empresas, com o apoio da mídia, colocam em circulação uma quantidade significativa de produtos para o consumo infantil, que vão desde artigos de vestuário, de alimentação até as mais elevadas criações tecnológicas.

Coutinho (2012) aponta que as mudanças culturais, oportunizadas pela combinação entre tecnologia e consumo, fazem emergir novas crianças no cenário social e configuram outra concepção de infância presente na atualidade: a das crianças consumidoras. No entanto, acreditamos que essa afirmação faz sentido somente quando nos reportamos, com maior ênfase, às infâncias urbanas. É preciso citar que há vários espaços geográficos que a tecnologia ainda não alcançou, bem como o acesso aos bens de consumo. Nesse sentido, citamos as crianças que são do campo e vivem sua infância no campo. Em que concepções estão sendo compreendidas?

Freire (2000) nos ajuda a fazer um contraponto quando pensamos nos meios de comunicação e na tecnologia e o uso que se faz delas. O referido teórico afirma a necessidade da compreensão crítica da tecnologia, uma vez que na contemporaneidade ela está infundida globalmente e disponível para todas 
as classes sociais. Nessa perspectiva, Freire (2000) defende que quanto maior vem sendo a importância da tecnologia hoje tanto mais se afirma a necessidade de rigorosa vigilância ética sobre ela. $\mathrm{O}$ autor, ao se referir à uma rigorosa vigilância ética, menciona uma ética a serviço de todas as pessoas e não uma ética do lucro e do mercado.

Dessa forma, reconhecemos a importância e legitimidade dos meios de comunicação como instrumentos de informação, de educação e de promoção da cidadania. No entanto, nossa intenção está em evidenciar que quando o uso desses meios não está sob uma vigilância ética eles contribuem para o processo de desumanização da infância. Como incluir todas as pessoas, as do campo e as das cidades para dialogar sobre a sociedade da informação? Como promover a humanização e a cidadania de todas as crianças com o auxílio da tecnologia e dos meios de comunicação?

$\mathrm{O}$ fato é que todo movimento da vida social contemporânea não tem contribuído para o reconhecimento da cidadania das crianças de diferentes classes sociais e condições geográficas e espaciais.

O Brasil com suas características multiculturais e multirraciais, nos permite olhar para diferentes infâncias e distintos jeitos de ser criança. Originariamente na sociedade brasileira as pessoas sofreram tratamento desigual. A forma de tratamento quase sempre foi definida de acordo com a raça, cor, classe social, dentre outros. As crianças brasileiras retratam as diferenças e formas de subjetivação na e da infância. É importante pensar nessa perspectiva, uma vez que é necessário oportunizar a compreensão das diferentes formas de ser e estar no mundo, com o mundo e com as outras pessoas e o reconhecimento das cidadanias negadas historicamente.

Para Freire (2005) a diferença não deveria ser condição das desigualdades, mas oportunidade para a humanização de todas as pessoas. O autor defende que

Aceitar e respeitar a diferença é uma dessas virtudes sem o que a escuta não pode se dar. Se discrimino o menino ou menina pobre, a menina ou o menino negro, o menino índio, a menina rica; se discrimino a mulher, a camponesa, a operária, não posso evidentemente escutá-las e não as escuto, não posso falar com eles, mas a eles, de cima para baixo. Sobretudo, me proíbo entendê-los. Se me sinto superior ou diferente, não importa quem seja, recuso-me escutá-lo ou escutá-la. O diferente não é o outro a merecer respeito é um isto ou aquilo, destratável ou desprezível. (FREIRE, 1996, p. 136)

Entendemos que a pedagogia freiriana, quando coloca em pauta a 
abordagem da diferença, assume um profundo compromisso com as lutas por humanização e resistência contra toda e qualquer forma de invasão cultural, imposição de valores e de dominação, condição de desumanização em relação à vida concreta das pessoas, logo assume um profundo compromisso com o reconhecimento e a garantia das cidadanias a partir dos espaços reais de produção da existência.

Além disso, essa abordagem da diferença potencializa o direito de ser, de viver e produzir diferença como uma exigência ontológica para o "ser mais", como o respeito a presença do outro no mundo, como elemento promotor da cidadania.

As infâncias do campo por muito tempo foram (e em alguns espaços continuam sendo) destituídas de suas cidadanias. Whitaker (2002) afirma que a infância do campo sempre existiu. No território brasileiro, talvez tenha surgido antes mesmo da infância urbana. Com base na afirmação de Whitaker (2002), consideramos que a concepção de infância, aquela compreendida como universal ou generalizada (citada no início do texto), também foi construída no alicerce de uma cultura e/ou ciência urbano-centrada. Logo, a infância do campo ficou subjugada a essa concepção e não foi considerada em suas especificidades.

Sob essa perspectiva, é importante promover o debate acerca dessa temática e discutir quais condições são necessárias para a constituição legitima da cidadania na infância. Esse debate pode contribuir para que a realidade da Educação de todas as crianças seja problematizada e modificada em prol da garantia dos seus direitos e da compreensão do seu status social.

Pensar a infância na contemporaneidade é dar visibilidade às crianças que participam de diferentes espaços, que recriam outras culturas e, a partir disso, nos permitem outras compreensões de infância. Sob esse olhar, se faz necessário pensar e reconhecer outros tempos e espaços de produção da infância e educação das crianças, espaços que têm emergido como formas de organização da própria sociedade civil.

Nesse sentido, na sequência, vamos apresentar e discutir, de maneira sucinta,algumas questões sobre a configuração da Educação do Campo no Brasil, bem como questões pertinentes aos povos do campo. Interpretamos que o reconhecimento do campo como espaço específico e legítimo de educação proporcionoue expandiu as possibilidades dos estudos sobre as infâncias, poisevidenciou os povos historicamente esquecidos social e academicamente. 


\section{OS POVOS DO/NO CAMPO E A LUTA POR PROCESSOS DE EQUIDADE SOCIAL: UMA POSSIBILIDADE PARA O RECONHECIMENTO DE CIDADANIAS}

De acordo com Fernandes (2011) o campo é um dos espaços da existência e da produção da vida humana. É o espaço onde pessoas moram, trabalham, estudam, se relacionam e produzem sua identidade cultural. É recente no Brasil, o reconhecimento de distintos povos e comunidades tradicionais do campo, tanto no aspecto da garantia de seus direitos, quanto da valorização de sua cultura. A história do campo brasileiro e dos povos do campo nem sempre foi compreendida, estudada e socializada como espaço de relações, de cultura e de produção de vida e de educação.

É importante salientar que durante bastante tempo a produção da vida no e do campo foi ocultada no sentido da falta de reconhecimento das especificidades, das demandas, da condição da existência das pessoas do campo. Foi a partir dos anos de 1980 que sensíveis mudanças relativas ao reconhecimento e da garantia dos direitos das pessoas, dentre elas das populações do campo, entram em discussão no Brasil. Segundo Cruz (2012), a Constituição de 1988, conhecida como "Constituição Cidadã", preconiza a garantia de direitos negados à maioria das pessoas no decorrer histórico do país.

Os povos do campo sempre existiram no Brasil, no entanto, suas especificidades no que diz respeito aos processos formais de educação não foram consideradas e/ou discutidas. Arroyo (2012), Caldart (2011) e Fernandes (2011) são consonantes em afirmar que os povos do campo devem ter o direito de estar e ser no mundo, de usufruir dos direitos a partir de sua realidade, do seu cotidiano e de sua cultura.

A partir do documento supracitado, ganham espaço no cenário político uma multiplicidade de vozes, de pessoas até então pouco considerados no decorrer histórico e na configuração das políticas públicas. A partir desse reconhecimento conceitos sobre o campo e sua educação culminaram na estruturação das Diretrizes Complementares, Normas e Princípios para o Desenvolvimento de Políticas Públicas de Atendimento da Educação Básica do Campo, aprovadas em $2008^{3}$, embora o termo Educação do Campo já tivesse

3 Sabemos que existem outras normativas direcionadas à Educação do Campo; elas serão devidamente citadas ao longo do texto. 
garantido um espaço de discussão desde o ano de 2002, quando da criação das Diretrizes Operacionais para a Educação Básica das Escolas do Campo DOEBEC (Resolução CNE/CEB nº 01/2002). Em 2008, a discussão se acentua e o termo Educação do Campo passa a ser definitivamente sancionado quando criadas as Diretrizes Complementares, Normas e Princípios para o Desenvolvimento de Políticas Públicas de Atendimento da Educação Básica do Campo (Resolução CNE/CEB nº 02/2008). Em 2009, a Educação Infantil também é contemplada nas discussões relativas à Educação do Campo e são revisadas as Diretrizes Curriculares Nacionais para Educação Infantil - DCNEI, pelo Conselho Nacional de Educação (Resolução CNE/CEB no 5/2009), a Educação Infantil se articula à Educação do Campo e passa a ser pensada no plano curricular (PELOSO, 2015).

As propostas regidas pela Educação do Campo foram concebidas como um direito, como uma proposta na qual o principal objetivo é igualdade de direitos. Por isso, exige o reconhecimento do que lhe é peculiar, da cultura, dos saberes e dos modos de produção da vida no/do campo. Caldart (2011) explica que a Educação do Campo nomeia um fenômeno da realidade brasileira atual. Esse fenômeno é protagonizado pelos povos do campo e objetiva participar da política de educação a fim de contemplar os interesses sociais e as especificidades das comunidades camponesas.

$\mathrm{Na}$ Resolução CNE/CEB n 2/2008, são descritas as populações do campo, sejam elas: agricultores familiares, extrativistas, pescadores artesanais, ribeirinhos, assentados e acampados da reforma agrária, quilombolas, caiçaras, indígenas e outros, como os povos e comunidades tradicionais.

A diversidade dos povos do campo nos convida a pensar sobre sua história e suas diferentes organizações. Podemos afirmar que cada povo tem sua cultura, sua forma de ser e estar no mundo, bem como tem sua forma de estabelecer relações com outras comunidades/sociedades.

Sabe-se que as populações indígenas foram as primeiras a habitarem o Brasil. Maracci (2012) sustenta que o termo "povos indígenas" originariamente é uma expressão genérica que faz referência aos grupos humanos provenientes de determinado país, região ou localidade. Ribeiro (1977) explica que no decorrer da história do Brasil as populações indígenas foram obrigadas a sofrer processos de aculturação e tiveram suas cidadanias negadas ao que compete às condições de equidade na garantia de direitos. Maracci (2012) complementa que há muitos povos indígenas e que são diferentes entre si. A diferença se dá sobretudo no fato de que cada povo se identifica com uma coletividade que 
exprime características próprias. Essas coletividades se diferem do conjunto da sociedade nacional em que se inserem justamente por suas particularidades e concepções de mundo e existência, que nem sempre foram respeitadas e reconhecidas como socialmente válidas.

Diegues (1988) nos explica que o termo caiçara é utilizado para identificar os moradores ou comunidades do bioma da Mata Atlântica dos litorais dos Estados do Paraná, São Paulo e Rio de Janeiro. O mesmo autor menciona que o termo caa-içara (caa significa galhos e içara significa armadilha) é de origem Tupi-Guarani e, inicialmente, era utilizado para denominar as estacas colocadas em torno das tabas ou aldeia. A população caiçara é originária da mistura dos portugueses com os indígenas e constituí a história brasileira desde sua origem. Trata-se, sobretudo, de comunidades pequenas que subsistem dos recursos naturais presentes em seu entorno.

Os povos ribeirinhos, de acordo com Silva e seus colaboradores (2012), são os povos que moram próximos aos rios e têm características de intimidade com as águas que os cercam. Dois aspectos específicos definem a organização social desse povo: 1) a utilização do transporte fluvial como principal meio de locomoção; e 2) o extrativismo vegetalprincipalmente a borracha, a pesca artesanal e o cultivo de pequenos roçados para a sua própria subsistência. Os mesmos autores socializam que os povos ribeirinhos estão espalhados em diversos Estados brasileiros, principalmente na região Norte do país, na Floresta Amazônica.

Wanderley (1995), conceitua a agricultura familiar como a organização da produção em que a família é proprietária e produtora ao mesmo tempo. Veiga (1995) explica que essa condição cria padrões de organização social, bem como processos educativos. Isso porque as condições de trabalho articuladas com base nas relações familiares consideram uma forma de organização bastante específica que leva em conta, sobretudo, a supremacia familiar e os ciclos de vida, dentre outros.

Ferreira (2012) nos explica que no Brasil colonial, eram conhecidas por quilombolas as pessoas de origem e/ou descendência africana que se colocavam contrárias às situações de escravidão, fugiam e se refugiavam em florestas e regiões de difícil acesso. Os quilombos se constituem como espaços de resistência no que diz respeito à soberania cultural de raça. A garantia desse entendimento sobre os quilombos também foi asseverada pela Constituição de 1988, quando as comunidades quilombolas são entendidas e, teoricamente, respeitadas a partir de sua historicidade e cultura e os quilombolas ganham o 
status de sujeitos de direitos a partir da especificidade de suas formas de ser e estar no mundo. Segundo a Fundação Cultural dos Palmares, do Ministério da Cultura, há no Brasil 3.524 comunidades quilombolas espalhadas pelo território nacional. Dessas, mais de 2.000 são certificadas pela Fundação.

De acordo com Cruz (2012), os povos e as comunidades tradicionais do campo constituem coletivos de: povos indígenas, quilombolas, populações agroextrativistas, grupos vinculados aos rios ou ao mar, grupos associados a ecossistemas específicos e grupos associados à agricultura ou à pecuária. Em seu conjunto, imprimem uma caracterização socioantropológica de diversos grupos. Com base no Decreto no 6.040/2007, que prescreve a Política Nacional de Desenvolvimento Sustentável dos Povos e Comunidades Tradicionais, podemos defini-los como "grupos culturais diferenciados e que se reconhecem como tais, que possuem formas próprias de organização social, que ocupam e usam territórios e recursos naturais como condição para a sua reprodução cultural, social, religiosa, ancestral e econômica".

$\mathrm{Na}$ multiplicidade, especificidade e formas de organização das diferentes populações do campo se configuram também distintas infâncias, peculiares em suas formas de ser e estar no mundo. Infâncias que são plurais, que dão sentido e significado aos processos heterogêneos de constituição de experiências, de subjetivação. Essas infâncias nos deslocam de um conceito unânime de infância para um conceito plural e legítimo e nos direcionam a reconhecer outras cidadanias. Cidadanias que respondam construtiva e significativamente às distintas experiências dessas infâncias. Cidadanias constituídas a partir das especificidades dessas experiências culturais, sociais, estéticas, éticas, organizativas, dentre outras.

\section{CONSIDERAÇÕES FINAIS}

Este ensaio objetivou problematizar sobre as diferentes concepções de infância, com foco nas Infâncias do e no Campo, no sentido de provocar uma discussão que oportunize um repensar sobre a concepção de normalidade a respeito da infância e das crianças e que também permita o reconhecimento das cidadanias contemporâneas do e no campo. Para tanto, num primeiro momento apresentamos e discutimos questões sobre as concepções de infância, na sequência fizemos uma breve abordagem sobre a educação e os povos do campo.

Consideramos imprescindível pensar sobre como se dá o processo da infância das crianças do e no campo e como se afirma a sua identidade e sua 
cidadania. Essas crianças vivem e convivem em um cenário particular, marcado pela dificuldade de acesso aos serviços oferecidos pelo Estado, como saúde, escola e lazer. Em alguns casos, esse cenário também é marcado por situações de violência e, ao mesmo tempo, de esperança, de sonho e de luta, também de apropriação e expropriação, pois as crianças participam diretamente do trabalho familiar, o qual é compreendido como educativo.

Frente aos escritos neste texto, podemos dizer que as populações do campo, em especial as crianças, não tiveram seus direitos sociais e humanos garantidos em prol da constituição de suas cidadanias. No Brasil, esses direitos são previstos e assegurados pela Constituição de 1988 e, no caso das crianças, (re) afirmados no Estatuto da Criança e do Adolescente de 1990. Esses documentos atuam no sentido de garantir à criança o status de sujeito. É importante salientar que esses documentos não fazem distinção dente as diferentes formas de manifestação da infância, ou seja, asseguram os direitos prescritos para todas as crianças na mesma proporção.

Sob essa perspectiva, identificamos a necessidade de políticas públicas que contemplem os diferentes sujeitos do campo e sua especificidade. A especificidade a que nos referirmos faz menção ao reconhecimento do território de cada povo, da cultura, valores, de sua maneira de se relacionar com o tempo, com a terra, com as relações de parentesco, com seu corpo, seu trabalho, suas concepções de mundo, seus modos de serem mulheres, homens, crianças e suas maneiras de viverem e conceberem as infâncias.

Compreender as pessoas do campo a partir de suas especificidades e o campo como território onde há produção de condições de existência e como espaço de relações, logo um espaço social, atribui à necessidade de um novo projeto nacional. Um projeto que fortaleça as identidades dos povos do campo e respeite sua diversidade, de modo a promover, de fato, sua cidadania.

Encerramos este ensaio afirmando a necessidade e urgência de considerar as várias formas de constituição da infância, de ser e estar no mundo de distintas crianças e, dessa forma, colaborar para o registro de nossa história recente, social e cultural, para o reconhecimento das cidadanias contemporâneas. Acreditamos que quando não reconhecemos os processos de negação da existência, da invisibilidade e da condição inferior que algumas populações foram submetidas no processo de desenvolvimento do país, sua história fica incompleta. É urgente problematizar as formas construção e legitimação da cidadania. 


\section{REFERÊNCIAS}

ABRAMOWICZ, Anete; OLIVEIRA, Fabiana de. A Sociologia da Infância no Brasil: uma área em construção. Educação, Santa Maria, v. 35, n.1, p-39-52, jan./abr., 2010.

ARIÈS, Philippe. História social da criança e da família. 2.ed. Trad. Dora Flaksman. Rio de Janeiro: Livros Técnicos e Científicos, 1981.

ARROYO, Miguel González. Políticas de Formação de Educadores (as) do Campo. Cadernos Cedes, Campinas, vol. 27, n.72, p. 157-76, maio/ago., 2007.

Outros sujeitos, outras pedagogias. Petrópolis, RJ: Vozes, 2012a.

Corpos precarizados que interrogam nossa ética profissional. In: ARROYO, Miguel González; SILVA Maurício Roberto da. (orgs). Corpo Infância: exercícios tensos de ser criança; por outras pedagogias. Petrópolis, RJ: Vozes, 2012b. p. 23-54.

ARROYO, Miguel González; SILVA Maurício Roberto da. (orgs). Corpo Infância: exercícios tensos de ser criança; por outras pedagogias. Petrópolis, RJ: Vozes, 2012.

BRASIL. Constituição (1988). Constituição da República Federativa do Brasil. Brasília, DF: Senado Federal, 1988.

Diretrizes complementares, normas e princípios para o desenvolvimento de políticas públicas de atendimento da Educação Básica do Campo. Brasília, DF: MEC, 2008.

CALDART, Roseli Salete. Por uma Educação do Campo: traços de uma identidade em construção. In: ARROYO, Miguel González; CALDART, Roseli Salete; MOLINA, Mônica Castagna. (orgs). Por uma Educação do Campo. 5.ed. Petrópolis, RJ: Vozes, 2011. p. 147-58.

CRUZ, Valter do Carmo. Povos e Comunidades Tradicionais. In: CALDART, Roseli Salete [et al] (orgs). Dicionário da Educação do Campo. Rio de Janeiro, São Paulo: Escola Politécnica de Saúde Joaquim Venâncio, Expressão Popular, 2012. p. 594-600.

DIEGUES, Antônio Carlos Sant'Ana. Diversidade biológica e culturas tradicionais litorâneas: o caso das Comunidades Caiçaras. São Paulo: 
NUPAUB-USP, série documentos e relatórios de pesquisa n.5, São Paulo, 1988.

FERNANDES, Bernardo Mançano. Diretrizes de uma caminhada. In: ARROYO, Miguel González; CALDART, Roseli Salete; MOLINA, Mônica Castagna. (orgs). Por uma Educação do Campo. 5.ed. Petrópolis, RJ: Vozes, 2011. p. 133-45.

FERREIRA, Simone Raquel Batista. Quilombolas. In: CALDART, Roseli Salete [et al] (orgs). Dicionário da Educação do Campo. Rio de Janeiro, São Paulo: Escola Politécnica de Saúde Joaquim Venâncio, Expressão Popular, 2012. p. 64550 .

FREIRE, Paulo. Pedagogia da Autonomia: Saberes necessários à prática educativa. 21. ed. Rio de Janeiro: Paz e Terra, 1996.

Pedagogia do Oprimido. 40. ed. Rio de Janeiro: Paz e Terra, 2005.

Pedagogia da Indignação: cartas pedagógicas e outros escritos. São Paulo: Editora UNESP, 2000.

FREITAS, Marcos Cezar de. História Social da Infância no Brasil. 8ed. São Paulo: Cortez, 2011.

FREITAS, Marcos Cezar de; KUHLMANN JUNIOR, Moysés. Os intelectuais na história da infância. São Paulo: Cortez, 2002.

GIROUX. Henry Armand; MCLAREN, Peter. Por uma pedagogia crítica da representação. In: SILVA, T. T, da; MOREIRA, A. F. (orgs). Territórios Contestados: o currículo e os novos mapas políticos e culturais. 4. ed. Rio de Janeiro: Vozes, 1995, p. 144-58.

KRAMER, Sonia. Pesquisando Infância e Educação: um encontro com Walter Benjamin. In: KRAMER, Sônia; LEITE, Maria Isabel Ferraz Pereira (orgs). Infância: Fios e desafios da pesquisa. 7. ed. São Paulo: Papirus, 2003. p. 13-38.

MARACCI, Marilda Teles. Povos Indígenas. In: CALDART, Roseli Salete [et al] (orgs). Dicionário da Educação do Campo. Rio de Janeiro/São Paulo: Escola Politécnica de Saúde Joaquim Venâncio, Expressão Popular, 2012. p. 600.

MELLO, Roseli R. Aprendizagem Dialógica: aprofundando a compreensão teórica e ampliando as possibilidades educativas. CNPq- Edital Universal, 20102013, 2012. 
MULlER, Verônica Regina. História de crianças e infâncias: registros, narrativas e vida privada. Rio de Janeiro: Vozes, 2007.

PELOSO, Franciele Clara. Infâncias do e no campo: um retrato dos estudos pedagógicos nacionais, 2015. 222f. Tese (Doutorado em Educação). Universidade Federal de São Carlos. São Paulo, 2015.

POSTMAN, Neil. O Desaparecimento da Infância. Trad. Suzana Menescal de Alencar Carvalho e José Laurenio de Melo. Rio de Janeiro: Graphia, 1999.

PRIORE, Mary. Del. O cotidiano da criança livre no Brasil entre a Colônia e o Império. In: PRIORE, Mary. del (org). História das crianças no Brasil. 6. ed. São Paulo: Contexto, 2007. p. 84-106.

RAMOS, Fábio Pestana. A história trágico-maritíma das crianças nas embarcações portuguesas do século XVI. In: PRIORE, Mary. Del (org). História das crianças no Brasil. 6. ed. São Paulo: Contexto, 2007. p. 19-54.

RIBEIRO, Darcy. Os índios e a civilização: a integração das populações indígenas no Brasil moderno. 2. ed. Petrópolis: Vozes, 1977.

SARMENTO, Manuel Jacinto. Sociologia da Infância: correntes, problemáticas e controvérsias. Sociedade e Cultura 02, Cadernos do Noroeste, Série Sociologia, v.13, n. 2, p. 145-64, 2000.

. Sociologia da Infância: correntes e confluências. In: SARMENTO, Manuel Jacinto; GOUVEA, Maria Cristina Soares de (orgs). Estudos da Infância: educação e práticas sociais. Rio de Janeiro: Vozes, 2008, p. 17-39.

SILVA, Ana Paula Soares da; FELIPE, Eliana da Silva; RAMOS, Márcia Mara. Infâncias do Campo. In: CALDART, Roseli Salete et al. (orgs). Dicionário da Educação do Campo. Rio de Janeiro/São Paulo: Escola Politécnica de Saúde Joaquim Venâncio, Expressão Popular, 2012. p. 417-24.

STROPASOLAS, Valmir Luiz. Os significados do corpo nos processos de socialização de crianças e jovens do campo. In: ARROYO, Miguel González; SILVA Maurício Roberto da (orgs). Corpo Infância: exercícios tensos de ser criança; por outras pedagogias. Petrópolis, RJ: Vozes, 2012. p. 153-83.

VASCONCELLOS, Vera Maria Ramos de; SARMENTO, Manuel Jaciento. Infância (in)visível. Araraquara: Junqueira e Marin, 2007. p. 25-49. 
VEIGA, José Eli. Delimitando a agricultura familiar. Reforma Agrária, v. 25, n. 2-3, mai./dez., 1995. p. 129-41.

WANDERLEY, Maria de Nazareth Baudel. A agricultura familiar no Brasil: um espaço em construção. Reforma Agrária, v. 25, n. 2-3, mai./dez., 1995. p. 37-57.

WHITAKER, Dulce Consuelo Andreatta. Sociologia Rural: questões metodológicas emergentes. São Paulo: Letras à Margem, 2002.

\section{Aportes al reconocimiento de ciudadanías modernas: una aproximación desde la infancia y el campo}

El objetivo de este estudio es discutir sobre el reconocimiento de ciudadanías contemporáneas a partir de la infancia campesina y de la niñez vivida en el campo. Esta investigación se hace necesaria por demostrar las diferentes infancias y validar las experiencias vividas por personas que se encuentran en contextos que poseen un historial de gran desigualdad social, además de evidenciar la diversidad de espacios, de culturas de clase, étnicas, raciales, y otras donde se desarrolla la niñez. Este estudio está basado en una investigación teórica. Las consideraciones principales de este texto subrayan las maneras heterogéneas en las que se presentan las experiencias de los niños y la forma como ellos se las viven. Sin embargo, el concepto homogéneo de una infancia de origen europea, blanca, cristiana y urbana evidencia cómo se ocultan y se hacen invisibles algunas experiencias infantiles que han sido segregadas a lo largo de la historia, y que siguen siéndolo. La principal contribución de este trabajo de investigación se basa en el reconocimiento de la existencia de esas infancias que son ocultadas o poco consideradas y el reconocimiento de las ciudadanías contemporáneas, además del deseo y de la esperanza de que otros investigadores/as se inspiren aquí, y con eso puedan considerar y potenciar la infancia campesina y la niñez vivida en el campo en sus estudios y en las acciones subsiguientes de dicho estudio.

Palabras clave: Infancia. Niñez. Campo. Educación Campesina. Ciudadanías Contemporáneas. Diversidad. 
Contributions to the recognition of contemporary citizenships: an approach from childhood and the countryside

This study has the objective to discuss about the recognition of contemporaneous citizenship from the countryside childhoods. The justification of this research is focused on the need to give visibility to the different childhoods and to legitimize the experiences lived by the people on from historical contexts marked by social inequality. Also, it is equally intended to highlight the diversity of spaces, of class cultures, of ethnic groups, of races in between others in which the childhoods happen. It is a theoretical essay. The main considerations of this study underline the heterogeneities revealed by distinct childhoods and ways to be a child. In the same way, they highlight the invisibility and the hiding of the childhood experiences which were segregated along the history and that are still segregated when homogenized by a conception of childhood of an European origins and also with white, christian and urban features. The main contribution of this study consists on the recognition of the existence of the invisibilized childhoods or that poorly considered ones. Also, it contributes to the recognition of the contemporaneous citizenship, followed by the desire of inspire other researches to consider and potencialize the countryside childhoods in their studies and in their actions.

Keywords: Childhoods. Countryside. Countryside Education. Contemporaneous Citizenship. Diversity. 